
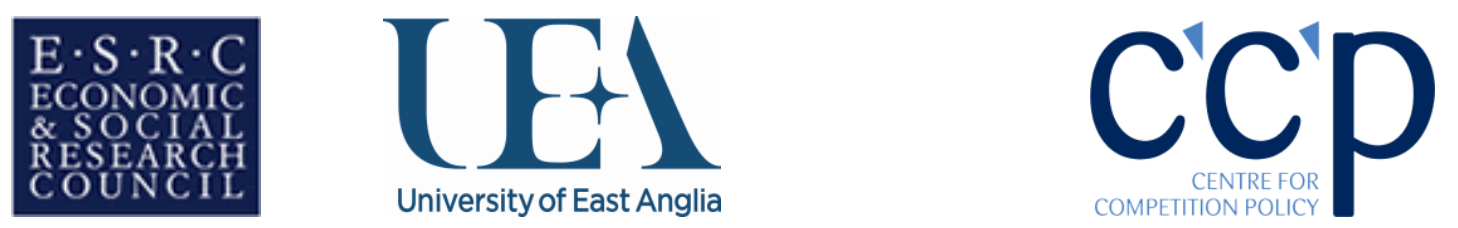

\title{
The Long-term Impact of Wind Power on Electricity Prices and Generating
}

\section{Capacity}

\author{
Richard Green \\ Department of Economics, University of Birmingham \\ $\&$ \\ Nicholas Vasilakos \\ Norwich Business School, University of East Anglia
}

\section{CCP Working Paper 11-4}

\begin{abstract}
This paper uses a market equilibrium model to calculate how the mix of generating capacity would change if large amounts of intermittent renewables are built in Great Britain, and what this means for operating patterns and the distribution of prices over time. If generators bid their marginal costs, we find that the changes to the capacity mix are much greater than the changes to the pattern of prices. Thermal capacity falls only slightly in response to the extra wind capacity, and there is a shift towards power stations with higher variable costs (but lower fixed costs). The changes to the pattern of prices, once capacity has adjusted, are relatively small. In an oligopolistic setting, strategic generators will choose lower levels of capacity. If wind output does not receive the market price, then mark-ups on thermal generation will be lower in a system with large amounts of wind power.
\end{abstract}

JEL Codes: L94, Q42

Keywords: Electricity Markets; Wind Generation; Intermittent output; Capacity mix; Capacity mix; Electricity prices; Long-term Equilibrium 
Acknowledgements: This research is funded by the Engineering and Physical Sciences Research Council and our industrial partners, via the Supergen Flexnet Consortium, Grant Number EP/E04011X/1. The views expressed are ours alone. We would like to thank audiences in Birmingham and at the IAEE European Conference 2010, Vilnius, for helpful comments. The support of the Economic and Social Research Council is gratefully acknowledged.

\section{Contact Details:}

Richard Green, Department of Economics, University of Birmingham, Birmingham, B15 2TT. Tel: +44 121415 8216, email: r.j.green@bham.ac.uk

Nicholas Vasilakos, Norwich Business School, University of East Anglia, Norwich, NR4 7TJ. Tel: +44 1603 593341, email: n.vasilakos@uea.ac.uk 
The Long-term Impact of Wind Power on Electricity Prices and Generating Capacity

\author{
Richard Green ${ }^{1}$ and Nicholas Vasilakos ${ }^{2,1}{ }^{*}$
}

\begin{abstract}
${ }^{1}$ Department of Economics University of Birmingham Birmingham , B15 2TT Tel: +441214158216 r.j.green@bham.ac.uk
\end{abstract}

\author{
${ }^{2}$ Norwich Business School \\ University of East Anglia \\ Norwich, NR4 7TJ \\ Tel: +44 1603593341 \\ n.vasilakos@uea.ac.uk
}

This paper uses a market equilibrium model to calculate how the mix of generating capacity would change if large amounts of intermittent renewables are built in Great Britain, and what this means for operating patterns and the distribution of prices over time. If generators bid their marginal costs, we find that the changes to the capacity mix are much greater than the changes to the pattern of prices. Thermal capacity falls only slightly in response to the extra wind capacity, and there is a shift towards power stations with higher variable costs (but lower fixed costs). The changes to the pattern of prices, once capacity has adjusted, are relatively small. In an oligopolistic setting, strategic generators will choose lower levels of capacity. If wind output does not receive the market price, then mark-ups on thermal generation will be lower in a system with large amounts of wind power.

Keywords: Electricity Markets, Wind Generation, Intermittent Output, Capacity Mix, Electricity Prices, Long-term Equilibrium.JEL Codes: L94, Q42

\footnotetext{
* This research is funded by the Engineering and Physical Sciences Research Council and our industrial partners, via the Supergen Flexnet Consortium, Grant Number EP/E04011X/1. The views expressed are ours alone. We would like to thank audiences in Birmingham and at the IAEE European Conference 2010, Vilnius, for helpful comments.
} 


\section{Introduction}

Over the coming decade, many countries are likely to experience a significant increase in the amount of wind generation. The European Union has committed itself to obtain $20 \%$ of its energy from renewable sources by 2020, and has published predictions showing that this might involve more than 500 TWh of wind generation, nearly seven times the current level. The output from wind generators is inevitably volatile, since their production is limited by the wind. Once wind power forms a significant part of an electricity market, this will feed through to short-run price volatility. When wind generation is high, prices will tend to be lower than normal, and when the wind is low, prices will tend to be higher.

In the short term, wind capacity has been added to a number of European markets without necessarily changing the amount of conventional capacity available. An increase in capacity will generally lead to a reduction in the margin between price and variable cost market monitoring strategies that study indices linked to the ratio between demand and capacity are based on this relationship. Sensfuß et al (2008) have calculated that the increase in capacity in Germany has led to a decline in wholesale prices sufficient to offset the cost of subsidising wind - in other words, the subsidies have effectively been paid by conventional generating companies rather than by electricity consumers. Sáenz de Miera et al (2008) have found a similar result for Spain, but also point out that the industry's conventional capacity will need to adjust to the growth in wind power, and that the long-term equilibrium will be one in which all types of plants can cover their costs from wholesale prices.

This paper asks what such a long-term equilibrium would look like in the case of the British electricity industry. With a peak demand of around $60 \mathrm{GW}$ at present, meeting the UK's target for renewable energy (15\% of all kinds of energy consumption) could well require the addition of $30 \mathrm{GW}$ of wind capacity (House of Lords, 2008). The equilibrium mix of conventional (and nuclear) capacity types with this level of renewable generation is likely to be very different from the mix which would be required without the investment in renewable energy. In particular, a higher proportion of the conventional stations can be expected to operate at relatively low load factors, since these will be needed to meet demand at times when the wind is below average, but only at those times. Plants with relatively low capital costs will therefore be favoured over those with low operating costs, compared to the mix associated with low levels of renewable output.

The total amount of conventional plant falls, but by much less than the amount of wind generation that is added. We find that the changes in conventional capacity effectively 
offset the impact of the wind generation on prices, and so the time-weighted average price is similar in the equilibria we find with and without wind generation. However, we find that this effect comes from an increase in the level and volatility of peak prices, combined with an increase in the number of hours in which demand is so low, relative to the output from "mustrun” plants, that some of these have to be constrained off the system and prices become negative. This means that the demand-weighted price does fall slightly. The average price received by each type of conventional plant is little changed (since these plants recover their costs), but the average across all conventional capacity rises, since there is a higher proportion of the plants with lower running times and higher average revenues. As a corollary, the price received by wind stations is much lower than the demand-weighted price (as predicted by Twomey and Neuhoff, 2010).

We also model an oligopoly with strategic bidding and investment behaviour and find similar changes to the capacity mix - combined cycle gas turbines replace nuclear stations. We do find, however, that the pattern of prices changes, with lower prices in hours with high levels of wind generation. We assume that our strategic firms do not own wind generators receiving the spot market price (either the wind generators are independent, or their revenues are independent of spot prices) and this reduces their incentives to raise prices in hours when wind generation has shifted their demand curve inwards. If (as is currently the case in Great Britain) the strategic thermal generators owned a large amount of wind generation receiving the spot market price, this effect of wind output on the price of power would probably be muted.

\section{Previous Work}

The techniques for capacity investment in a "traditional" electricity industry are wellestablished. A screening curve, such as in the top panel of Figure 1, shows the total costs per $\mathrm{kW}$-year of different types of capacity as a function of its load factor over the year. Typically, a technology like nuclear power will have relatively high fixed costs and relatively low variable costs, and so may be the cheapest option if high load-factor generation is needed; that is, to meet a demand that will last for most of the year. Open cycle gas turbine stations have very low fixed costs, and although their variable costs are high, it is still efficient to build them to meet demands that will only last for a short proportion of the year. Coal- and gas-fired stations (combined cycle gas turbines) typically have intermediate costs, 
and are the cheapest option for meeting demands that are neither base-load nor peaking. The exact load factor for which two technologies have identical costs, and hence the point at which generators would switch their choice between them, depends on the details of the stations' costs, and in particular the level of fuel prices. In some countries, where emissions are regulated via tradable permits, generators also have to take account of the cost of buying these, which will tend to raise the variable cost of polluting technologies.

Figure 1: The derivation of optimal capacity

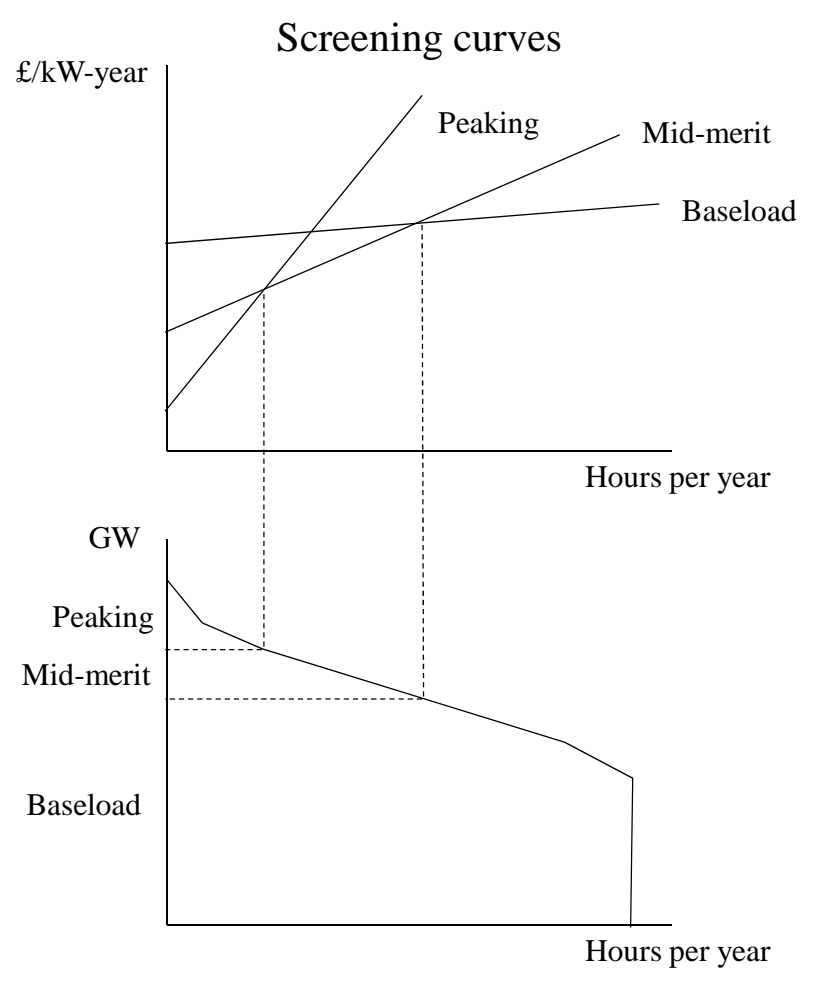

\section{Load-duration curve}

The screening curve could then be compared with the expected load-duration curve for the relevant time period, as in the bottom panel of Figure 1 - when making investment decisions which take time to implement, this period has to be several years in the future. In the traditional approach, a utility would aim to have enough capacity that the risk of power cuts would be kept to a very low level (in England and Wales, the standard was nine winters in a century, although the industry had excess capacity and the actual level of power cuts due to 
capacity shortages was below this level). The level of the other kinds of capacity was set so that each station could expect to be operating for a number of hours such that it would have lower costs than the alternatives. In other words, the number of nuclear plants would be kept low enough to ensure that they were all able to run on base load, and the number of coal- and gas-fired plants would be low enough to allow them to run for reasonably long periods in which their lower operating costs can offset the lower fixed costs of peaking plants.

This model can also be applied to investment decisions in a perfectly competitive, liberalised, electricity market. Stoft (2002) and Green (2005) are examples of how to do this. The key issue is that the market requires some kind of electricity auction that will set the price equal to the opportunity cost of power. When there is adequate capacity, this is equal to the marginal cost of generation. When there is not enough capacity to meet demand in full, this is equal to the opportunity cost of not doing so, or the marginal willingness to pay of the marginal consumer. Given certain simplifying assumptions and a perfectly competitive market without uncertainty, an electricity auction can be shown to provide the right incentives to generators to build the same level of capacity as the integrated utility ought to have chosen.

The model can be used to predict the long-term consequences of changes to the pattern of electricity demand, or the addition of particular types of generation capacity. One paper in this vein is Borenstein (2005). He estimates the potential impact of allowing some customers in the California electricity market to face real-time prices. The capacity mix and prices are derived in an equilibrium that also leaves the remaining customers paying the average cost of the power that they buy, creating a non-trivial set of calculations. Borenstein finds that the gains from adopting real-time pricing would be significant, that they would increase, the more elastic consumers' electricity demand turns out to be, and that the marginal gains from adding consumers to the real-time pricing programme would tend to decline as the number included rose.

Sáenz de Miera et al (2008) use this setting to comment on the long-run equilibrium impact of wind power on capacity and prices in the Spanish market, but do not actually calculate the equilibrium. Usaola et al (2009) provide some more of the analysis, showing that neither payments for providing capacity, nor average wholesale prices, should change. Lamont (2008) takes a system planning perspective, showing how the optimal mix of other plant types changes as renewables are added to a system modelled on California. He shows that the sum of marginal costs over the year will equal the costs (fixed and marginal) of the baseload generator. In a market system, this is equivalent to saying that the annual average 
price will not change. His simulations, however, concentrate on the capacity mix and on break-downs of total cost. Pöyry (2009) have used a model of the electricity system in Great Britain and Ireland to calculate operating patterns and prices for a scenario in 2030 with a high level of wind capacity. Their public report does not give full details of the modelling approach, but it appears that their core scenario is not a full equilibrium as presented in these other papers - in particular, as the level of wind capacity in the system rises, the load factors of various kinds of other stations falls. ${ }^{1}$ In the full equilibrium model, we shall see that the average load factor of each kind of station remains almost constant - it has to remain within the range for which that station is the lowest-cost solution. What changes is the mix of capacity which has to be built in order to accommodate the wind generators in a least-cost manner.

The closest paper to ours of which we are aware is Bushnell (2010). He uses a similar model, calibrated to the western United States, to model the impact of a large amount of wind generation, which he finds would displace a significant amount of mostly coal-fired generation. He also considers the choice between an energy-only market and a system with a capacity market. While we have mentioned the theoretical ability of energy-only markets to produce the optimal capacity mix, in reality, they seem at risk of failing to do so (Joskow, 2008). Instead, several electricity markets in the US include a capacity market in an attempt to create the correct incentives for generators (Cramton and Stoft, 2005). Bushnell finds that the equilibrium levels of thermal investment are insensitive to the choice of market design, but that wind generators receive higher payments with a capacity market. In an energy-only market, prices are typically highest in hours with little wind generation, reducing the wind generators' average revenues. With a capacity market, these prices are capped, and the missing money is repaid in proportion to generators' available capacity. The payments to wind capacity are discounted for its lower average availability, but the wind generators still earn more than in the energy-only market.

In this paper, we abstract from the choice between an energy-only market and one which includes a capacity market, implicitly assuming that the latter (if adopted) would produce the revenues that the idealised energy-only market was supposed to. Given the (officially) binding nature of the UK's renewable energy targets, we assume that any changes in revenues to wind generators would be offset, if necessary, by changes to their non-market

\footnotetext{
${ }^{1}$ For example, the load factor for new CCGTs falls from 70\% in 2010 to 50\% in 2025.
} 
income. Instead, we model the impacts of demand responsiveness, nuclear flexibility and market power.

\section{The Model: Competitive Case}

We have presented key parts of our model graphically in the previous section, but it can also be formulated mathematically. The objective function is to choose the level of each type of capacity, $k_{i}$, and the output produced by that capacity in each hour, $q_{i t}$, in order to maximise social welfare, equal to the (gross) surplus from consuming electricity, less the fixed and variable costs of its production. The surplus from consuming electricity is given by the integral of the inverse demand function, $p_{t}\left(Q_{t}\right)$, where $Q_{t}$ is the total consumption in that hour. The fixed cost of capacity type $i$ is given by $F_{i}$, and its variable cost per unit of output by $v_{i}$.

We consider several operating constraints. First, the output from each type of power station cannot exceed its available capacity, which is some portion $a_{i t}$ of its total capacity. We use $i$ to denote the types of plant (including $n$ for nuclear, and $w$ for wind) and $t$ to denote time periods. For thermal stations, we set $a_{i t}$ equal to 0.9 in the winter season (October to March) and equal to 0.8 in the summer (April to September) when demand is typically lower and more maintenance is carried out. For wind stations, the available capacity varies by hour, and we describe its calculation below. Second, nuclear power stations have a minimum load constraint: it is not technically feasible to operate them at less than a proportion $m$ of their available capacity. The value of $m$ varies by the type of station, but we assume that all the stations in our long-run equilibrium will be Pressurised Water Reactors, for which a value of 0.6 is appropriate (Pouret et al, 2009). Third, a given amount of electricity must be generated by stations which are capable of responding (practically immediately) to changes in the balance of generation and demand (most often from breakdowns somewhere in the system), and other stations must be held in reserve, read to start or to increase output at short notice. We group these requirements together, and require the output from non-nuclear stations to equal or exceed $r$ in all hours, setting $r$ equal to 5,000 MW. We also include $r$ in an overall capacity requirement - available capacity must exceed the level of demand $\left(Q_{t}\right)$ plus reserves. Our optimisation problem is thus: 


$$
\begin{array}{rlrl}
\operatorname{ck}_{k_{i}, q_{i t}} W & =\sum_{t=1}^{T} \int_{0}^{Q_{t}} p_{t}(q) d q-\sum_{i=1}^{I}\left[F_{i} k_{i}+\sum_{t=1}^{T} v_{i} q_{i t}\right] & \\
\text { s.t. } Q_{t} & \leq \sum_{i=1}^{I} q_{i t} & & \forall t \\
q_{i t} & \leq a_{i t} k_{i} & \forall i, t \\
q_{n t} & \geq m a_{n t} k_{n} & \forall t \\
r & \leq \sum_{i \neq n} q_{i t} & \forall t \\
Q_{t}+r & \leq \sum_{i=1}^{I} q_{i t} & \forall t
\end{array}
$$

We solve the model by implementing the first order conditions derived from this problem. In periods with spare capacity, the price of electricity is equal to the variable cost of the most expensive kind of capacity which is either operating or providing reserve, with two exceptions. Some thermal capacity is always operating to meet the reserve requirement, but if there is nuclear capacity which is not running, the price of electricity is equal the variable cost of nuclear rather than of the conventional stations. (The revenues those thermal stations receive in these hours is calculated on the assumption that they are paid the variable cost of the most expensive thermal station being used, however.) If the minimum load constraint on nuclear stations is binding, then some wind generation will be constrained off, and the price of power will be equal to the opportunity cost of the subsidy forgone, which we set to £40/MWh. ${ }^{2}$ If all available capacity is required, then the price rises to the level needed to ration demand to this capacity.

The overall level of generation capacity is chosen so that the rents from periods in which the price exceeds variable cost are just equal to the fixed cost of the peaking capacity, and so that type of capacity just breaks even. ${ }^{3}$ Within this total, the amount of each type of capacity is chosen so that it just breaks even, receiving the market price as described above. ${ }^{4}$

\footnotetext{
${ }^{2}$ This is based on the current system of support, which issues Renewables Obligation Certificates which can be sold to supplement the generators’ market price. We take $£ 40 / \mathrm{MWh}$ as a long-term equilibrium for this price, which the government aims to keep at a premium to its buy-out level of £36.99 per ROC (in 2010-11).

${ }^{3}$ The peaking capacity will normally consist of open cycle gas turbines, but it is possible that there will be so many hours in which demand is at the level of total capacity that it would be more economic to run a combined
} 
Our wind output and demand data is taken from Green and Vasilakos (2010). It is based on hourly wind speed data from the British Atmospheric Data Centre for 1993 to 2005, for weather stations around Great Britain. Missing data points were interpolated, or derived from local regressions on the wind speeds measured at other nearby stations. We then used a standard turbine power curve to calculate the hourly wind output per MW of capacity in the region of each weather station. The wind speeds were uniformly scaled up or down to produce annual load factors that corresponded to those observed in practice, using a variant of the procedure adopted by Oswald et al (2008).

The demand levels we used are based on those observed during the same period, scaled up to 2020 values (assuming continued demand growth of $1.1 \%$ per year from the end of our data period). The scaling between past demands and 2020 levels is based on the annual energy requirements, and therefore preserves the weather-related variation in demand levels. In other words, we take the demand that the weather conditions of (say) noon on 4 January 2003 might produce, were they to occur at midday on a January day in 2020, and subtract the wind output that the same conditions would generate, assuming our distribution of wind capacity. This gives us one observation for the hourly net electricity demand.

In Green and Vasilakos (2010) our focus is on the hour-to-hour variation in prices and year-to-year variation in profits caused by fluctuating wind levels, and so we needed to treat the data for individual years separately. In this paper, our first focus is on long-run tendencies, and so we start by combining all of our demand and wind data into a single loadduration curve for each season (winter and summer), when deriving the best capacity mix. However, once the industry is committed (at least in the short term) to a given capacity mix, year-to-year variations in output could be important, and so we also model their impacts by considering each year separately, for a fixed capacity mix. Figure 2 shows our load-duration curves over the entire sample. We have reversed them, moving from lowest to highest demand hours as we move from left to right, so that the top of the curve is not obscured by the vertical axis.

cycle gas turbine for this number of hours, in which case CCGTs rather than OCGTs will be the peaking capacity type.

${ }^{4}$ If there are 5 types of capacity and we have already determined the total amount, we naturally only need to determine the individual capacities for four of the plant types, obtaining the fifth as a residual. 


\section{Load-duration curves}

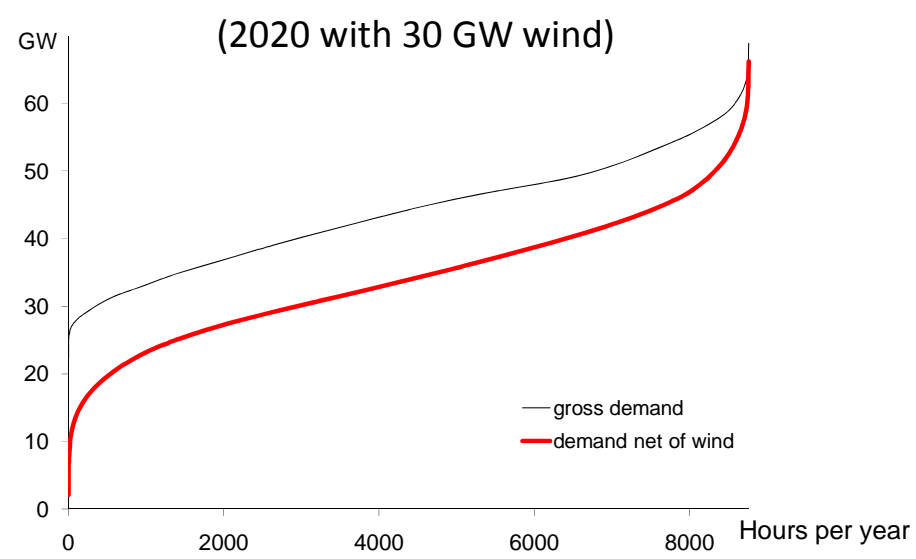

Figure 2: Load duration curves

The key factors affecting the choice of plant are the variable and fixed costs of the different technologies. A wide range of estimates of fixed costs are available - we have taken ours from the most recent study done for the UK government (Mott Macdonald, 2010). We consider five plant types: nuclear, combined cycle gas turbines (CCGT), supercritical coal (with and without carbon capture and sequestration) and open cycle gas turbines (OCGT). In each case, we use the figures for " $n$ of a kind" new build plant ordered in 2017 (i.e., after the first of a kind costs have been incurred). Our intention is to study the costs of the marginal plants of each type, the ones that would determine the long-run equilibrium capacity mix.

We assume that all carbon permits are auctioned, which obviously increases the variable costs of all the fossil-fuelled plant. We take a carbon price of $£ 70$ per tonne of CO2, a gas price of $£ 29 / \mathrm{MWh}$, and a coal price of $£ 9 / \mathrm{MWh}$; at these prices, it turns out that both kinds of coal plants are uneconomic, given the fixed costs assumed by Mott Macdonald. (We assume that the price of gas is $7 \%$ above this annual average in winter, and $7 \%$ below it in summer.) The key figures for each plant type are shown in TableTable 1.

Formatted: Font: Not Bold 


\begin{tabular}{|l|r|r|r|}
\hline Plant type & $\begin{array}{l}\text { Thermal } \\
\text { efficiency }\end{array}$ & $\begin{array}{l}\text { Non-fuel variable cost } \\
(£ / \text { MWh })\end{array}$ & $\begin{array}{l}\text { Fixed cost } \\
(£ / \mathrm{kW} \text { per year })\end{array}$ \\
\hline Nuclear & $\mathrm{n} / \mathrm{a}$ & 2.80 & 479.4 \\
\hline CCGT & 0.59 & 63.61 & 117.5 \\
\hline Coal unabated & 0.45 & 49.98 & 294.1 \\
\hline Coal with CCS & 0.36 & 32.27 & 482.5 \\
\hline OCGT & 0.40 & 91.93 & 74.1 \\
\hline
\end{tabular}

Table1: The costs of different generating technologies

Given these costs, nuclear power stations were the lowest-cost option for running times of between 5,000 and 8,760 hours a year and combined cycle gas turbines were the lowest-cost option for operating between 1,800 and 5,000 hours a year. For operating periods of less than 1,800 hours a year, the cheapest option was to build Open Cycle Gas Turbines.

Many of the stations that will be operating in 2020 have already been built, of course, and will have lower thermal efficiencies, and hence higher operating costs, than the state-ofthe art plants that we model for new investments. This would imply that marginal costs, and hence prices, would be higher when these stations were operating than when new plants were on the margin, with consequent effects on investment. In the simulations presented here, however, we assume that all capacity of a given type has identical costs. We wish to concentrate on the nature of the long-run equilibrium rather than on the pathway leading to it.

\section{Results - competitive market}

We start by modelling a competitive market, in which prices essentially track marginal costs except at full capacity. ${ }^{5}$ We use straight line demand curves with two different slopes. Our competitive simulations are based on a slope of $-2 \mathrm{MW}$ per $£ / \mathrm{MWh}$ increase in price. While this gives a very low elasticity for most of the price and demand combinations we obtain, it implies that the peak demand falls by around $10 \%$ in response to prices rising above variable cost, a level of demand response that is much higher than currently occurs, but could be

\footnotetext{
${ }^{5}$ In practice, our spreadsheet model uses the supply function equilibrium described in the following section, but with a very large number of firms (600) which ensures that the equilibrium function follows marginal costs very closely.
} 
promoted by future "smart grid" technologies. We also use a more responsive demand curve with a slope of $-5 \mathrm{MW}$ per $£ / \mathrm{MWh}$.

We solve the model twice for each case. First, we take the total predicted demand for power in 2020, and find the optimal capacity mix, based on our combined load-duration model. For practical purposes, this implies first choosing the total capacity, since that gives us the level of peak prices, and contribution to the fixed costs of peaking plant. We can subtract the amount of Open Cycle Gas Turbine plant from this total to give us the highest demand that will be met by CCGT plant, and hence the lowest load factor of those plants. This needs to be the load factor at which CCGT and peaking plants have the same costs. In practice, if we have the right amount of CCGT (and cheaper) capacity (in terms of variable costs), it will make approximately zero profits. ${ }^{6}$ We then derive the amount of CCGT plants that ensures the marginal coal-fired plant will make zero profits, and finally the amount of nuclear plant that can run more cheaply than a coal-fired generator. We then repeat the exercise for the demand net of our predicted wind output.

\section{Equilibrium capacity mix \\ (varying demand response)}

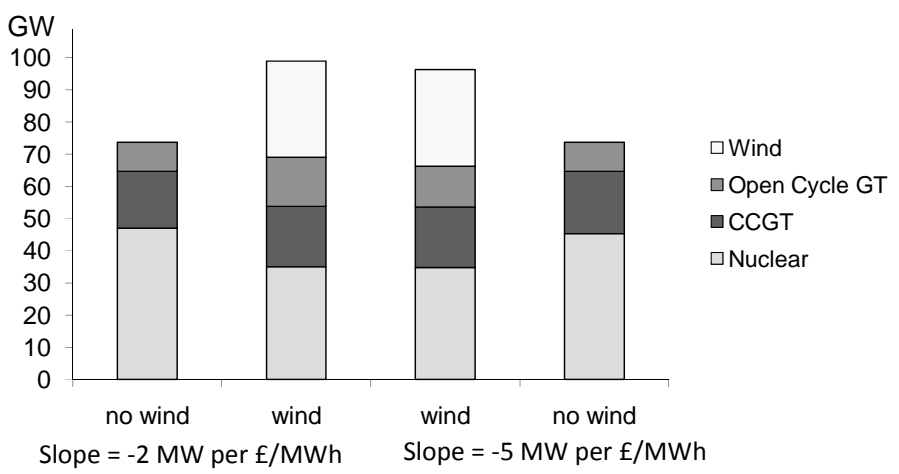

Figure 3: Equilibrium capacity mixes

The results are shown in the left-hand columns of Figure 3. Note that building $30 \mathrm{GW}$ of wind leads to a slight decrease in the equilibrium amount of thermal capacity, but that the

\footnotetext{
${ }^{6}$ This can only be an approximation, since we are using a stepped, rather than continuous, load-duration curve.
} 
amount of total capacity rises significantly. Furthermore, there is a big reduction in the amount of nuclear capacity - higher wind outputs at times of low overall demand affect these stations' chances of running for long enough to recover their high fixed costs.

The columns on the right of the diagram represent a less inelastic demand curve, which has a flatter slope (demand falls by $5 \mathrm{MW}$ per £/MWh increase in price, as opposed to $2 \mathrm{MW}$ ). In equilibrium, this requires slightly less capacity in total than the more elastic scenarios. We shall see below that peak prices are lower with this demand slope, but occur in a greater number of hours. Effectively, demand adjusts more to high prices, which means that the highest prices cannot be as high, and so more of them are required if generators are to recover their fixed costs.

\section{Price duration curves base case assumptions}

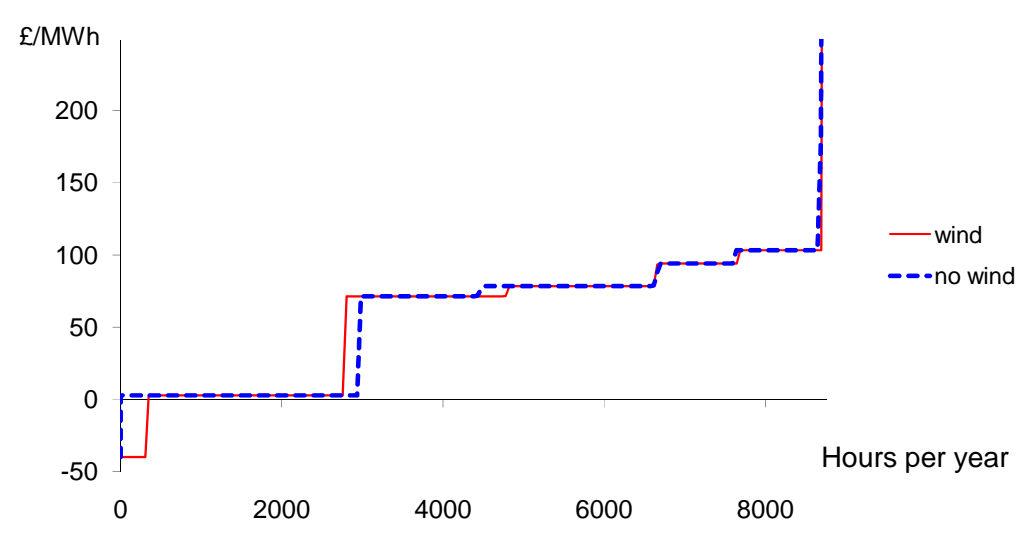

Figure 4: Price duration curves for the base case

Figure 4 shows the price duration curve for the base case (a demand slope of -2 MW per £/MWh), truncating the curve at a price of $£ 250 / \mathrm{MWh}$ for clarity. It shows that the two curves are very similar. The solid line representing prices with $30 \mathrm{GW}$ of wind capacity has more hours in which nuclear generation is constrained at its minimum level and faces a negative price (there are very few in the case without wind generation). To compensate, the price must rise to the variable cost of CCGT plants for slightly more hours - a reduction in 
the amount of nuclear capacity, relative to the level of demand for thermal plants in those hours, ensures this. We can infer the maximum and minimum load factor for each kind of plant from the steps in the price duration curve - these show the points in the year at which each plant in turn stops being marginal. The load factor for the marginal plants of each type do not change by large amounts as we add wind generation, because their capacities have adjusted to it. Furthermore, the average load factors for each type of plant are also practically unchanged. The load factor for nuclear stations falls from $81.9 \%$ to $80.2 \%$; that for CCGTs from $54.1 \%$ to $53.1 \%$, and the load factor for OCGTs rises from $7.4 \%$ to $4.7 \%{ }^{7}$

\section{Price duration curves (detail) base case assumptions}

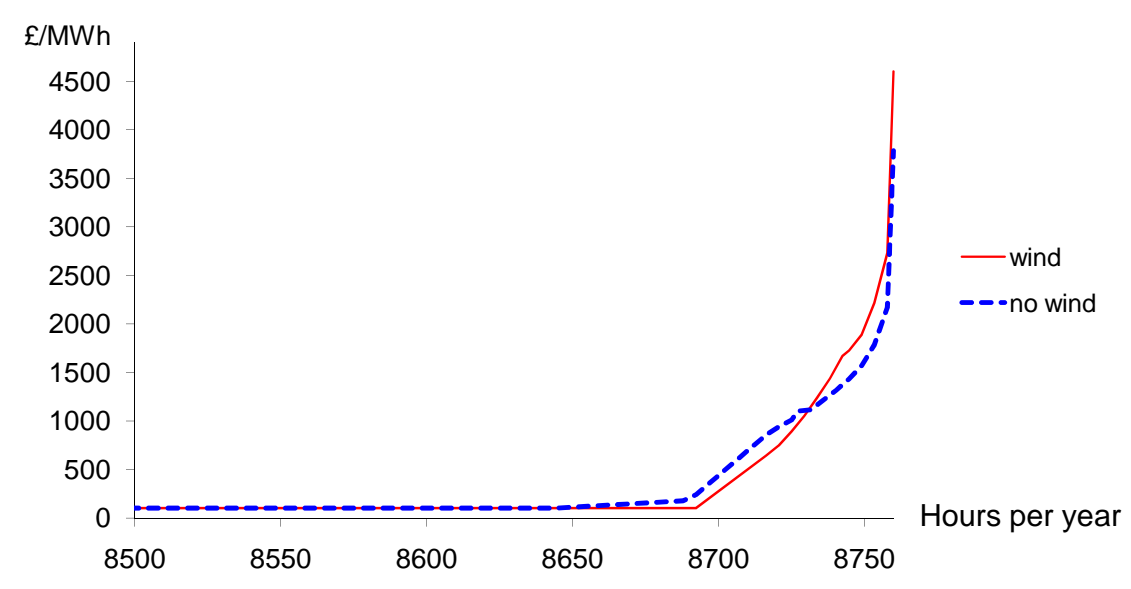

Figure 5: Price duration curves: detail of highest prices in base case

Figure 5 shows the top end of the price duration curve, in which very high prices occur. The highest prices are in the scenario with wind generation; without wind generation, prices are not as high at the very peak, but are higher in the next cohort of hours. Effectively, if the peaking stations do not receive enough revenue to cover their fixed costs in the highest few

\footnotetext{
${ }^{7}$ While each of these average load factors depends on the shape of the load-duration curve within the range for which the plant type is the least-cost option, and this will change as wind output rises, modelling approximations may also be responsible for part of the changes we report.
} 
hours of the year, then prices must remain above their variable costs for a greater number of hours, albeit at more modest levels.

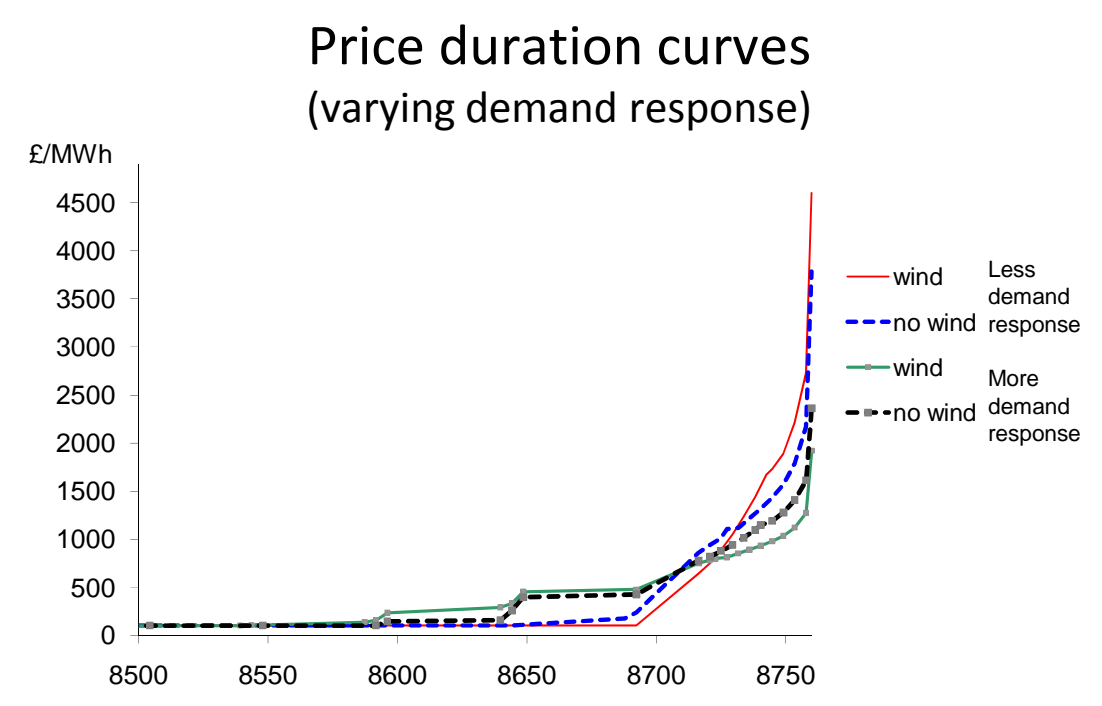

Figure 6: Price duration curves (detail) showing the impact of demand response

Figure 6 shows the impact of assuming different levels of demand response, again concentrating on the highest-priced hours. The top two lines (at the right hand end), with less responsive demand, duplicate those in Figure 5, whereas the two lower lines are for the more responsive demand. The relationship between the cases with and without wind generation is similar; and with more responsive demand, prices must remain above variable cost for a larger number of hours if generators are to recover their fixed costs. 

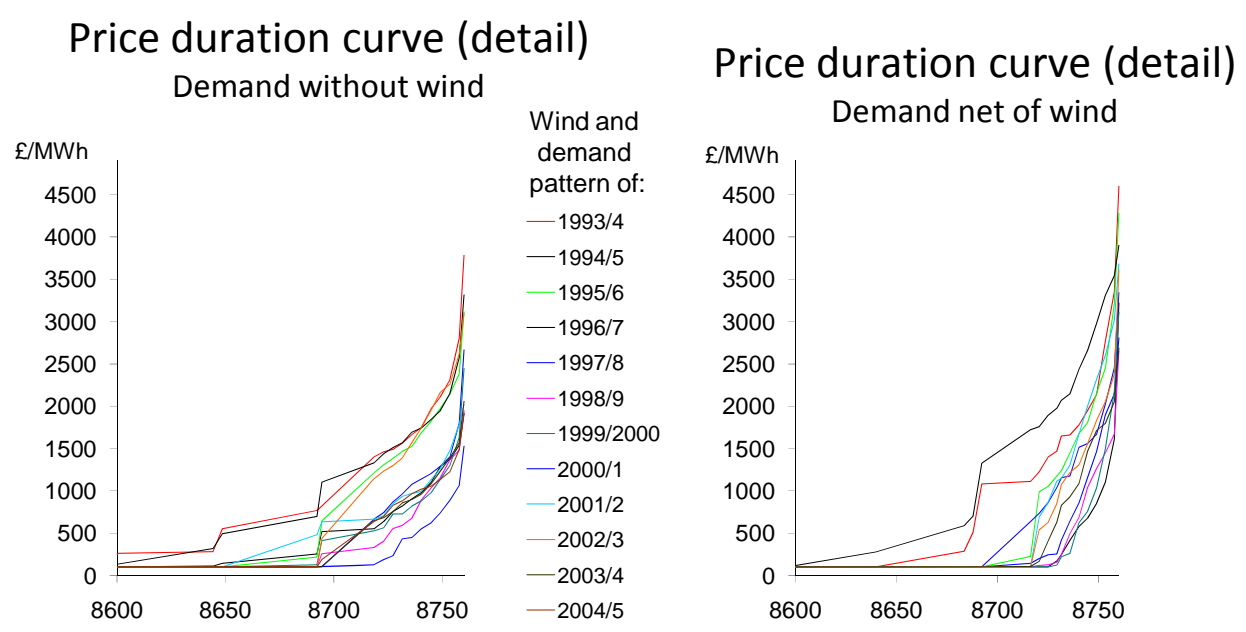

Figure 7: Annual price duration curves (detail) with and without wind generation

Figure 7 shows how the price-duration curve might vary from year to year, combining historic patterns of demand and wind, but both scaled up to reflect 2020 values. The capacity mixes are still fixed at the levels optimal over the entire sample. The left-hand side shows the scenario without wind generation, whereas the right-hand panel shows the higher prices seen with wind generation. Comparing equal-ranked hours (those within the top 60 hours per year) across the 13 years in our sample, we find more variation when there is wind generation: the mean standard deviation rises from £450/MWh to £580/MWh.

Table 2 gives several (weighted) measures of the mean price for our four scenarios (with and without wind, and with different levels of demand response). We find that the time-weighted average price hardly changes, since it is anchored by the average costs of baseload plant (as described by Lamont (2008)). The demand-weighted price is slightly lower in the scenarios with wind generation; this is because there is more wind generation (which tends to reduce prices) in high- than in low-demand hours, on average. If there is no wind generation, thermal generators as a whole receive the demand-weighted price (with a baseload generator receiving the time-weighted price, and a peaking station much more), but their average revenues are much higher in the scenarios with wind. This is because the highest prices (for given levels of demand) are in the hours with little wind output and hence relatively high levels of thermal generation. Finally, we see that the wind generators receive 
much less than the time-weighted average price, since their output is concentrated in hours of relatively low prices. The level of demand response has little impact on these average prices.

\begin{tabular}{|c|c|c|c|c|c|}
\hline & & $\begin{array}{l}\text { Time- } \\
\text { weighted }\end{array}$ & $\begin{array}{l}\text { Demand- } \\
\text { weighted }\end{array}$ & Thermal plant & $\begin{array}{l}\text { Wind } \\
\text { generators }\end{array}$ \\
\hline \multirow{2}{*}{$\begin{array}{l}\text { Demand } \\
\text { slope }-2\end{array}$} & No wind & $£ 66 / \mathrm{MWh}$ & £76/MWh & $£ 76 / \mathrm{MWh}$ & $\mathrm{n} / \mathrm{a}$ \\
\hline & Wind & £66/MWh & £73/MWh & $£ 84 / \mathrm{MWh}$ & £30/MWh \\
\hline \multirow{2}{*}{$\begin{array}{l}\text { Demand } \\
\text { slope }-5\end{array}$} & No wind & $£ 66 / \mathrm{MWh}$ & $£ 76 / \mathrm{MWh}$ & $£ 76 / \mathrm{MWh}$ & $\mathrm{n} / \mathrm{a}$ \\
\hline & Wind & $£ 66 / \mathrm{MWh}$ & £72/MWh & $£ 83 / \mathrm{MWh}$ & £30/MWh \\
\hline
\end{tabular}

Table 2: Average prices, £/MWh

Since year-to-year variations in wind output imply noticeable differences in the annual priceduration curves, it should not be surprising that this feeds in to the generators' profits. While each kind of generator would earn annual profits of close to zero against our averaged loadduration curve, there is a substantial range between the highest and lowest years in our sample. As Table 3 shows, however, the ranges are not in fact much greater for the scenarios with a large and varying wind output and those with no wind. The implication would seem to be that variations in the level of wind output from year to year do not have much more impact than the existing year-to-year variations in demand.

\begin{tabular}{|l|l|l|l|}
\hline & & $\begin{array}{l}\text { Variation without } \\
\text { wind }\end{array}$ & $\begin{array}{l}\text { Variation with } \\
\text { wind }\end{array}$ \\
\hline $\begin{array}{l}\text { Nuclear } \\
\text { plant }\end{array}$ & Slope -2 & $£ 73$ to $-£ 69$ & $£ 98$ to $-£ 85$ \\
\cline { 2 - 4 } & Slope -5 & $£ 65$ to $-£ 52$ & $£ 95$ to $-£ 75$ \\
\hline $\begin{array}{l}\text { OCGT } \\
\text { stations }\end{array}$ & Slope -2 & $£ 62$ to $-£ 57$ & $£ 96$ to $-£ 49$ \\
\cline { 2 - 4 } & Slope -5 & $£ 55$ to $-£ 39$ & $£ 92$ to $-£ 40$ \\
\hline
\end{tabular}

Table 3: Variation in annual profits, $£$ per $\mathrm{kW}$ (range between maximum and minimum)

\section{Oligopoly}

We repeat our modelling exercise for a less competitive industry, one with an oligopoly of six symmetric firms, a scenario that represents the current state of the UK market reasonably well. Instead of setting price equal to variable cost when demand is less than capacity, we 
use the supply function equilibrium introduced by Klemperer and Meyer (1989), adapting the version reported in Green and Vasilakos (2010). In particular, the supply function is obtained as a solution to the maximisation problem of the representative firm's profit function:

$$
\pi(p, t)=p\left(D(p, t)-\sum_{j \neq i} q_{j}(p)\right)-C_{i}\left(D(p, t)-\sum_{j \neq i} q_{j}(p)\right)
$$

where $p$ denotes the market price selected at each time, $D(p, t)$ is the market demand at time $t$ and $q_{j}(p)$ the supply function submitted by firm $j$, so that $D(p, t)-\sum_{j \neq i} q_{j}(p)$ is the residual demand faced by firm $i$ at time $t$, and $C_{i}(q)$ represents the cost for firm $i$ of producing $q$ units of output. Solving through first order condition for this problem gives the supply function, which takes the form:

$$
q_{i}(p)=\left(p-C_{i}^{\prime}\left(q_{i}(p)\right)\right)\left(-\frac{\partial D}{\partial p}+\sum_{j \neq i} \frac{\partial q_{j}}{\partial p}\right)
$$

The model calculates the industry supply function, rather than individual firm functions "as if" its conventional and nuclear plant was divided among symmetric firms, while the output from renewable generators is netted off from demand. This avoids the problem of calculating a supply function which sifts with the out-turn level of wind output, but implies we have to treat wind generators as if they are independent of conventional generation (which is not true for many UK generators) or as if they are paid a fixed feed-in tariff, irrespective of market prices. This is indeed the case in many EU countries, and is being considered by the UK government in its consultation on electricity market reform. We use the more responsive of our two demand curves, with a slope of $-5 \mathrm{MW}$ per £/MWh; even this produces prices which would be very likely to provoke a regulatory response in practice.

The overall level of capacity will be chosen by profit-maximisation - extra capacity allows a firm to produce very slightly more at peak times, but this reduces the revenues earned by the rest of its capacity, and incurs fixed costs. This means that the profitmaximising amount of capacity is less than the amount in the previous scenarios, as shown in Figure 8. 


\section{Equilibrium capacity mix \\ (varying market structure)}

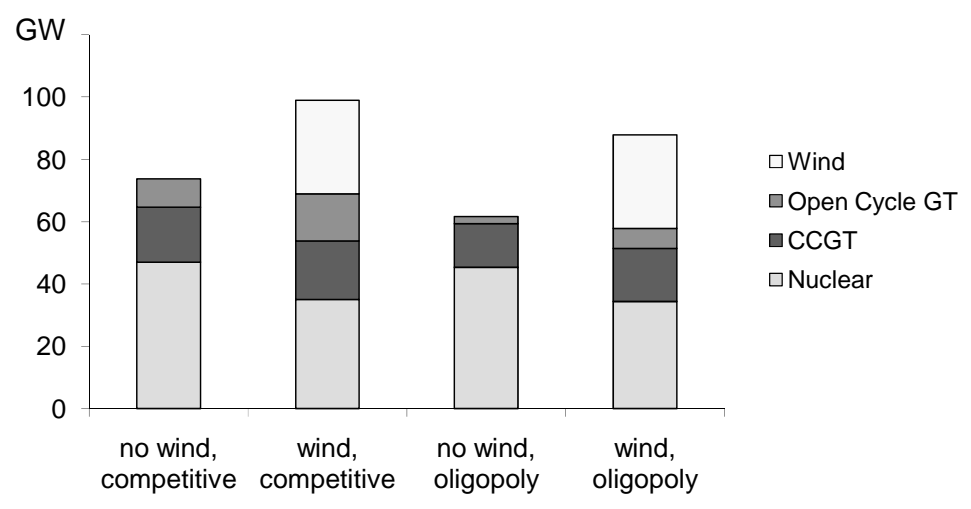

Figure 8: Capacity mix in competitive and oligopoly cases.

The generators reduce their capacity significantly in the strategic cases, almost eliminating the use of Open Cycle Gas Turbines (if there is no wind), and reducing their capacity of CCGT stations. At the same time, in most cases there is little change in the amount of nuclear capacity. This is because the firms will choose their capacity mixes to minimise costs. Changing the firm's marginal cost over a range of output (e.g. by replacing some nuclear output by gas-fired) will affect its profits directly by changing those costs. There might also appear to be an indirect effect, in that the firm's profits depend on its price bid, and this depends on the level of its marginal costs. By the envelope theorem, however, we don't need to consider the impact of the firm's changing bid on its profits, since the bid was optimal, implying that $\frac{\partial \pi}{\partial p}=0$.

Figures 9 and 10 show that the resulting price-duration curves involve much higher prices (and hence profits) than the competitive cases. In part, this is because the strategic firms submit higher price bids for any given level of capacity than a competitive industry would, but this effect is magnified by the strategic decision to under-invest. This is slightly mitigated, for the cases with a large amount of wind power, by our assumption that the 
strategic generators do not own any wind stations receiving the spot market price. This means that they are selling less power in the spot market in the cases with wind generation and have less incentive to raise this price.

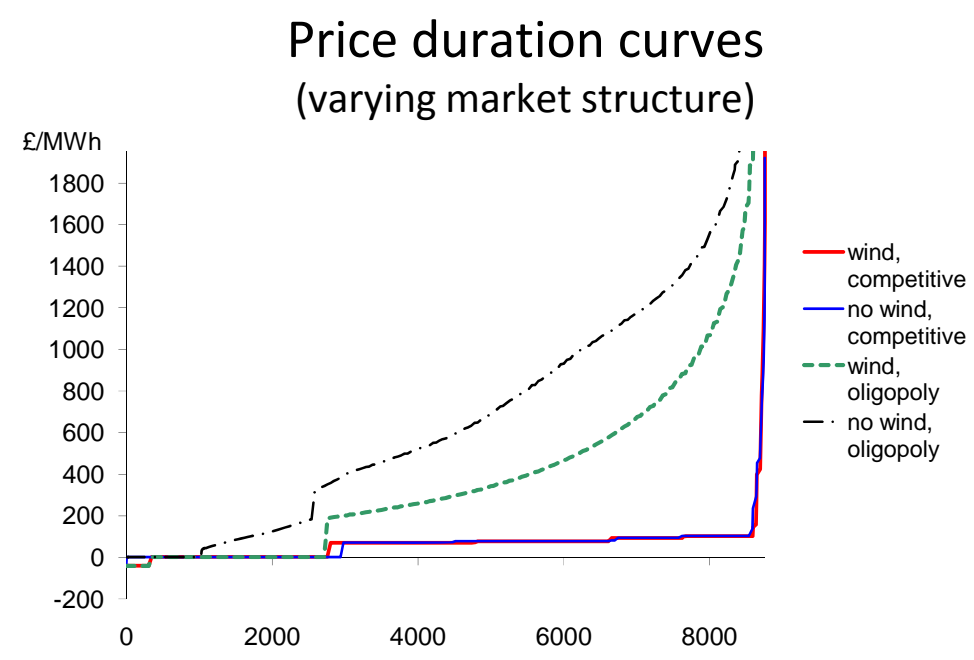

Figure 9: Price duration curves with strategic firms.

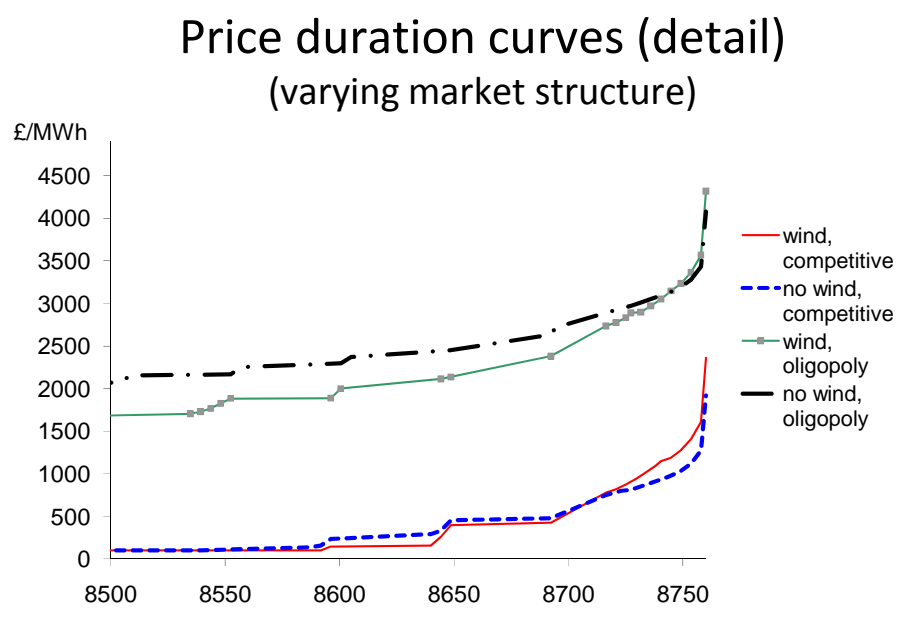

Figure 10: Price duration curves (detail) with strategic firms. 
We suspect that prices at the levels predicted in our oligopoly case would trigger regulatory intervention, and that firms which expected this would show more restraint in both their pricing and (under-) investment decisions. They might also provoke entry, even though the degree of vertical integration in the British electricity market makes this harder. Both arguments were invoked by Green and Newbery (1992) to suggest that actual wholesale prices would be below the highest levels predicted in their model, which turned out to be the case.

\section{Conclusions and policy implications}

What does this model show us? First, that if the industry was to reach a long-term equilibrium (or even tend towards one), the introduction of large amounts of wind generation would tend to change the mix of the rest of the generation fleet. This model is not designed to look at the technical task of scheduling generators to meet the demand for power, but part of the task of adjusting to volatile levels of wind output will be managed by changing the mix of generating capacity, rather than relying on changed operating patterns from an unchanged generation fleet to provide all of the necessary response. However, the model in this paper is not intended to shed light on the details of this task, or its costs.

Second, despite the changes to the industry's capacity mix, there will be a substantial amount of capacity which will only run for relatively short periods, and will require high prices during those periods to recover its fixed costs from an energy-only market (such as the ones used in Great Britain, and in much of Europe). If the energy-only market design would be placed under greater strain, it would be worth looking at other possibilities, including the ways of paying for capacity that have been adopted in some (but not all) of the liberalised electricity markets in the United States. The UK government has indeed included options for supporting peaking capacity in its 2010 consultation on electricity market reform (DECC, 2010) .

Third, increasing the responsiveness of demand to prices would appear to be an essential tool for reducing the amount of rarely-used capacity required (since demand response can be a substitute for this) and in mitigating the abuse of market power.

Fourth, year-to-year variations in wind speeds will have some impact on electricity prices and generators' profits, but these are smaller than those that have resulted from variations in fuel prices over the last ten years. Modelling the several sources of uncertainty 
together, and combining them to analyse a portfolio of generation plant, is a useful area for further research.

\section{References}

Borenstein, S. (2005) “The Long-Run Efficiency of Real-Time Electricity Pricing” Energy Journal, vol. 26, no. 3, pp. 93-116

Bushnell, J. (2010) "Building Blocks: Investment in Renewable and Nonrenewable Technologies” in (eds.) R. Schmalensee, J Padilla and B. Moselle, Harnessing Renewable Energy, London, Earthscan

Cramton, P. and S. Stoft (2005) “A Capacity Market That Makes Sense” Electricity Journal, vol. 18, no. 7, pp 43-54

Department for Energy and Climate Change (2010) Electricity Market Reform: Consultation Document, Cm 7983, London, The Stationery Office

Green, R.J. (2005) “Electricity and Markets” Oxford Review of Economic Policy, vol. 21, no.1, pp. 67-87

Green, R.J, and D.M. Newbery (1992) 'Competition in the British Electricity Spot Market' Journal of Political Economy vol. 100 no 5, pp 929-53

Green, R.J. and N. Vasilakos (2010) "Market Behaviour with Large Amounts of Intermittent Generation” Energy Policy, vol. 38, no. 7, pp. 3211-3220

House of Lords (2008) The Economics of Renewable Energy, Economic Affairs Select Committee Fourth Report of Session 2007-8, HL195 of 2007-8, London, The Stationery Office

Joskow, P.L. (2008) “Capacity payments in imperfect electricity markets: Need and design”, Utilities Policy, vol. 16, pp. 159-170

Klemperer, P. D. and M.A. Meyer, (1989) "Supply Function Equilibria in Oligopoly under Uncertainty”, Econometrica, 57(6) Nov. 1243-1277

Lamont, A.D. (2008) "Assessing the long-term system value of intermittent electric generation technologies” Energy Economics, vol. 30, no. 3, pp. 1208-1231

Oswald, J. M. Raine, and H. Ashraf-Ball (2008) "Will British weather provide reliable electricity?” Energy Policy, vol. 36, no. 8, pp. 3212-3225.

Pouret, L., N. Buttery and W.J. Nuttall (2009) “Is nuclear power inflexible?” Nuclear Future, vol. 5 no. 6 , pp. 333-340 
Pöyry (2009) The Impact of Intermittency: How wind variability could change the shape of the British and Irish electricity markets Summary report, Oxford, Pöyry Energy Consulting

Sáenz de Miera G., P. del Río González, and I. Vizcaíno (2008) “Analysing the impact of renewable electricity support schemes on power prices: the case of wind electricity in Spain” Energy Policy, vol. 36, no. 9, pp. 3345-3359.

Sensfuß, F.; M. Ragwitz and M. Genoese (2008) “The Merit-order effect: A detailed analysis of the price effect of renewable electricity generation on spot market prices in Germany” Energy Policy, vol. 36, no. 8, pp. 3076-3084.

Stoft, S.E. (2002) Power System Economics: Designing Markets for Electricity Chichester, Wiley

Twomey, P. and K. Neuhoff (2010) "Wind power and market power in competitive markets" Energy Policy, vol. 37 no. 7, pp. 3198-3210

Usaola, J., J. Rivier, G. Sáenz de Miera, M.Á. Moreno, and M. Bueno (2009) Effect of Wind Energy on Capacity Payment: The Case of Spain, $10^{\text {th }}$ IAEE European Conference, Vienna 